\title{
A COLEÇÃO AMARELA DA LIVRARIA DO GLOBO (1931-1956)i
}

\author{
Coleção Amarela, PUblished by LiVRARIA Do GLOBO
}

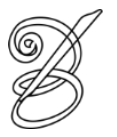 \\ Sérgio Bandeira KARAM ${ }^{\mathrm{ii}}$ \\ Mestrando em Letras \\ Universidade Federal do Rio Grande do Sul (UFRGS) \\ Porto Alegre, Rio Grande do Sul, Brasil \\ sbkaram@uol.com.br \\ Denise Guimarães BOTTMANN ${ }^{\text {iii }}$ \\ Tradutora e Mestre em História \\ São Paulo, São Paulo, Brasil \\ dbottmann@gmail.com
}

Resumo: Este artigo tem por objetivo apresentar o levantamento completo de todos os volumes publicados pela Coleção Amarela, da Livraria do Globo de Porto Alegre, ao longo de seus quase 26 anos de existência. Nele constam os títulos publicados, seus respectivos autores, tradutores e capas, bem como o número do volume dentro da coleção e o ano de primeira edição.

Palavras-chave: Literatura policial. Tradução. Indústria editorial.

Abstract: This article intends to present a complete survey of the titles published by Porto Alegre's Livraria do Globo in its Coleção Amarela, a collection of detective novels that lasted almost 26 years. In this survey, we can find the published titles, their authors, translators, and frontcovers, as well as the number assigned to each volume inside the collection and its year of edition.

Keywords: Detective novels. Translation. Publishing

\section{Apresentação}

Coleção Amarela, publicada entre 1931 e 1956 pela Livraria do Globo, de Porto A Alegre, foi a mais importante coleção de romances policiais a ser publicada no

Brasil. Importante não só pelo número de títulos que lançou (exatamente 151, descontando-se os sete títulos duplicados entre os 158 volumes lançados, de 38 autores diferentes), mas também por sua longevidade (durou mais de 25 anos) e pelo fato de ter lançado alguns autores que estão entre os melhores do gênero. Só para estabelecermos uma comparação, a Companhia Editora Nacional publicou apenas 24 volumes em sua Série Negra, também dedicada exclusivamente ao romance policial, entre 1934 e 1938, além de ter lançado cerca de 30 títulos policiais na primeira fase da Coleção Paratodos, também nos anos 30.

Do ponto de vista do total de títulos traduzidos pela Livraria do Globo entre 1926 e 1986, quando é vendida à Rio Gráfica, a Coleção Amarela também foi bastante significativa: 
seus 151 títulos representam cerca de um terço dos 456 títulos de literatura traduzida publicados pela editora gaúcha em suas diversas coleções, segundo o levantamento realizado por Sônia Amorim. Apenas a Coleção Nobel, dedicada à literatura estrangeira, foi tão significativa em termos numéricos: 128 títulos publicados entre 1933 e 1958.

Finalmente, deve-se destacar o trabalho dos tradutores: entre os vários profissionais que se dedicaram à tradução tanto dos volumes lançados pela Coleção Amarela quanto daqueles lançados pela Coleção Nobel, encontramos os nomes de Mario Quintana, Erico Verissimo, Leonel Vallandro e Lino Vallandro. Sem o seu trabalho, certamente seria mais pobre a história da tradução literária no Brasil.

\section{Listagem}

Aqui se tem pela primeira vez o levantamento completo de todos os volumes publicados pela Coleção Amarela, ao longo de seus quase 26 anos de existência. Nele constam os títulos publicados, seus autores e respectivos tradutores, bem como o número do volume dentro da coleção e o ano de primeira edição.

214 Como há de se observar na relação abaixo, dos finais de 1937 até 1949 ocorreram vários atrasos na programação de lançamentos, gerando defasagens e discrepâncias entre a numeração das obras e a data de lançamento. Tais ocorrências estão destacadas em negrito, na coluna do ano de publicação. Notar-se-á também que, por razões inexplicadas, o volume de número 125 nunca chegou a sair, dado este que vem destacado também em negrito.

Quatro títulos - a saber, os volumes 16, 43, 76 e 99 - não trazem créditos de tradução, e vêm assinalados por N/C [não consta]. No entanto, foi possível rastrear documentalmente a identidade do tradutor do volume 76, Assassinato no expresso do Oriente, de Agatha Christie: Silvia Guaspari, cujo nome foi acrescentado entre colchetes. Marcação similar tem-se no volume 8, A série sangrenta, cujos créditos de tradução aparecem atribuídos às iniciais M.G. - acrescentou-se entre colchetes o nome de Marina Guaspari, aqui neste caso constando como a hipótese mais provável.

A partir de 1951, quando a Coleção Amarela já entrava em declínio, registram-se vários relançamentos de títulos publicados anteriormente na mesma coleção. Tais ocorrências estão indicadas entre colchetes, como [reed. v. $x$ ]. 


\begin{tabular}{|c|c|c|c|c|}
\hline Vol. & Autor & Título & Tradutor & Ano \\
\hline 1 & Wallace, Edgar & O círculo vermelho & Darcy Azambuja & 1931 \\
\hline 2 & Wallace, Edgar & A porta das sete chaves & Pedro Bruno Dischinger & 1931 \\
\hline 3 & Wallace, Edgar & $O$ sineiro & Erico Verissimo & 1931 \\
\hline 4 & Wallace, Edgar & O bando terrível & A. Duprat & 1931 \\
\hline 5 & Mason, A. E. W. & O prisioneiro da Opala & F. Marques Guimarães & 1931 \\
\hline 6 & Wallace, Edgar & O homem sinistro & Erico Verissimo & 1931 \\
\hline 7 & Wilton, Louis & A aranha branca & Walter Heckmann & 1931 \\
\hline 8 & Van Dine, S. S. & A série sangrenta & M.G. [Marina Guaspari] & 1932 \\
\hline 9 & Wallace, Edgar & $O$ anjo do terror & Marina Guaspari & 1932 \\
\hline 10 & Wilton, Louis & A rainha da noite & Cristovam L. Paledzki & 1932 \\
\hline 11 & Rinehart, Mary R. & $\begin{array}{l}\text { O mistério da escada } \\
\text { circular }\end{array}$ & Erico Verissimo & 1932 \\
\hline 12 & Wallace, Edgar & O abade negro & Suzana Burtin-Vinholes & 1932 \\
\hline 13 & $\begin{array}{l}\text { Oppenheim, E. } \\
\text { Phillips }\end{array}$ & Um crime em Glenlitten & Pepita de Leão & 1932 \\
\hline 14 & Van Dine, S. S. & O crime da canária & Darcy Azambuja & 1932 \\
\hline 15 & Wilton, Louis & O tapete da morte & $\begin{array}{l}\text { Pedro Bruno } \\
\text { Deschinger }\end{array}$ & 1932 \\
\hline 16 & Freeman, R. Austin & O mistério D'Arblay & $\mathrm{N} / \mathrm{C}$ & 1932 \\
\hline 17 & Rohmer, Sax & A mão de Fu-Manchu & Leonel Vallandro & 1932 \\
\hline 18 & Rohmer, Sax & A garra amarela & J. de Souza & 1932 \\
\hline 19 & Wallace, Edgar & A estranha condessa & Carmen Annes Dias & 1932 \\
\hline 20 & Van Dine, S. S. & O caso Benson & Pepita de Leão & 1932 \\
\hline 21 & Rohmer, Sax & Lingua de fogo & Orlando Maia & 1932 \\
\hline 22 & Wallace, Edgar & O fantasma verde & Marieta Silva & 1932 \\
\hline 23 & Fletcher, J. S. & O mistério Mazaroff & Cacy Cordovil & 1933 \\
\hline 24 & Wallace, Edgar & Na pista do alfinete novo & Erico Verisssimo & 1933 \\
\hline 25 & Rohmer, Sax & O escorpião de ouro & Pedro Nunes & 1933 \\
\hline 26 & Freeman, R. Austin & O incrivel Dr. Thorndyke & Lourival Cunha & 1933 \\
\hline 27 & Christie, Agatha & O trem azul & J. de Souza & 1933 \\
\hline 28 & Crofts, F. Wills & O sindicato Pit-Prop & Lourival Cunha & 1933 \\
\hline
\end{tabular}




\begin{tabular}{|c|c|c|c|c|c|}
\hline & 29 & Christie, Agatha & $\begin{array}{l}\text { O assassinato de Roger } \\
\text { Ackroyd }\end{array}$ & Heitor Berutti & 1933 \\
\hline & 30 & Freeman, R. Austin & Como um ladrão à noite & Pedro Bruno Dischinger & 1934 \\
\hline & 31 & Crofts, F. Wills & O caso Ponson & $\begin{array}{l}\text { Carmen de Revoredo } \\
\text { Dias }\end{array}$ & 1934 \\
\hline & 32 & Van Dine, S. S. & O bispo preto & Peri Pinto Diniz & 1934 \\
\hline & 33 & Rinehart, Mary R. & O homem do leito no. 10 & Lourival Cunha & 1934 \\
\hline & 34 & Wallace, Edgar & A morte mora em Chicago & Erico Verissimo & 1934 \\
\hline & 35 & Fletcher, J. S. & O mistério de Markenmore & Sonja Campani & 1934 \\
\hline & 36 & Rohmer, Sax & A filha de Fu-Manchu & Erico Verissimo & 1935 \\
\hline & 37 & Varaldo, Alessandro & O sete belo & Luiz Estrella & 1935 \\
\hline & 38 & Wallace, Edgar & Gangsters & J. de Souza & 1935 \\
\hline & 39 & Wilton, Louis & As panteras & Walter Heckmann & 1935 \\
\hline & 40 & Christie, Agatha & A casa perdida & Pepita de Leão & 1935 \\
\hline & 41 & Wallace, Edgar & A cobra amarela & Erico Verissimo & 1936 \\
\hline & 42 & Rohmer, Sax & O imperador da América & Pepita de Leão & 1936 \\
\hline & 43 & Wilton, Louis & O sinal fatídico & $\mathrm{N} / \mathrm{C}$ & 1936 \\
\hline & 44 & Crofts, F. Wills & O mistério de Groote Park & Leonel Vallandro & 1936 \\
\hline & 45 & Horler, Sydney & O pior homem do mundo & J. de Souza & 1936 \\
\hline & 46 & Fletcher, J. S. & O vaso chinês & $\begin{array}{l}\text { Suzanne Burtin- } \\
\text { Vinholes }\end{array}$ & 1936 \\
\hline & 47 & Eberhart, Mignon G. & O crime dum aristocrata & $\begin{array}{l}\text { Suzanne Burtin- } \\
\text { Vinholes }\end{array}$ & 1936 \\
\hline & 48 & Wallace, Edgar & Os três homens justos & Leonel Vallandro & 1936 \\
\hline & 49 & Horler, Sydney & Senhorita Mistério & Leonel Vallandro & 1937 \\
\hline & 50 & Rohmer, Sax & O espectro da cara cinzenta & Heitor Almada & 1937 \\
\hline & 51 & $\begin{array}{l}\text { Oppenheim, E. } \\
\text { Phillips }\end{array}$ & As joias dos Ostrekoff & Lilia Guaspari & 1937 \\
\hline & 52 & Wallace, Edgar & $\begin{array}{l}\text { O homem que não era } \\
\text { ninguém }\end{array}$ & "Gilberto Miranda" & 1937 \\
\hline & 53 & Le Queux, William & Garra de cristal & $\begin{array}{l}\text { Suzanne Burtin- } \\
\text { Vinholes }\end{array}$ & 1937 \\
\hline
\end{tabular}




\begin{tabular}{|c|c|c|c|c|}
\hline 54 & Rohmer, Sax & Asa de morcego & $\begin{array}{l}\text { Carmen de Revoredo } \\
\text { Dias }\end{array}$ & 1937 \\
\hline 55 & Wells, Carolyn & Os três punhais & Silvia Guaspari & 1938 \\
\hline 56 & Wallace, Edgar & O aventureiro & Ernestina Black & 1937 \\
\hline 57 & Wallace, Edgar & A esmeralda quadrada & "Gilberto Miranda" & 1937 \\
\hline 58 & $\begin{array}{l}\text { Crofts, Freeman } \\
\text { Wills }\end{array}$ & A carga macabra & "Gilberto Miranda" & 1938 \\
\hline 59 & Varaldo, Alessandro & A gata persa & Mario Quintana & 1938 \\
\hline 60 & Wallace, Edgar & O caso da dama apavorada & Leonel Vallandro & 1938 \\
\hline 61 & $\begin{array}{l}\text { Oppenheim, E. } \\
\text { Phillips }\end{array}$ & O segredo de Martin Hews & "Gilberto Miranda" & 1938 \\
\hline 62 & Crofts, F. Wills & Morte repentina & Arno Von Muhlen & 1938 \\
\hline 63 & Wallace, Edgar & A inteligência de Mr. Reeder & "Gilberto Miranda" & 1939 \\
\hline 64 & Fletcher, J. S. & Um cadáver no jardim & Justino Martins & 1939 \\
\hline 65 & Wallace, Edgar & A volta do sineiro & Lilia Guaspari & 1938 \\
\hline 66 & Rohmer, Sax & Mão decepada & Lídia Brockmann & 1938 \\
\hline 67 & Wallace, Edgar & A fita verde & Silvia Guaspari & 1938 \\
\hline 68 & Christie, Agatha & As 4 potências do mal & Marina Guaspari & 1939 \\
\hline 69 & Wallace, Edgar & O mistério do "Polyantha" & Lília Guaspari & 1938 \\
\hline 70 & Rohmer, Sax & Sombras amarelas & Leonel Vallandro & 1938 \\
\hline 71 & Wallace, Edgar & Máscara branca & Silvia Guaspari & 1939 \\
\hline 72 & Horler, Sydney & Vivanti & Lilia Guaspari & 1938 \\
\hline 73 & Wallace, Edgar & Os 4 homens justos & Radagasio Taborda & 1939 \\
\hline 74 & Rohmer, Sax & Tóxico! & Juvenal Jacinto & 1939 \\
\hline 75 & Wallace, Edgar & A esquadra volante & "Gilberto Miranda" & 1942 \\
\hline 76 & Christie, Agatha & $\begin{array}{l}\text { Um crime no expresso do } \\
\text { Oriente }\end{array}$ & N/C [Silvia Guaspari] & 1940 \\
\hline 77 & Wallace, Edgar & O terror & Antônio Barata & 1940 \\
\hline 78 & Packard, Frank L. & As aventuras de Jimmie Dale & Leonel Vallandro & 1939 \\
\hline 79 & Wallace, Edgar & Trapaceiros em alto mar & Marques Rebello & 1940 \\
\hline 80 & Horler, Sydney & A casa dos segredos & Fay de Azevedo & 1940 \\
\hline 81 & Wallace, Edgar & A volta dos 3 homens justos & Liberato Soares Pinto & 1940 \\
\hline
\end{tabular}




\begin{tabular}{|c|c|c|c|c|c|}
\hline & 82 & Packard, Frank L. & $\begin{array}{l}\text { As novas proezas de Jimmie } \\
\text { Dale }\end{array}$ & $\begin{array}{l}\text { Aydano do Couto } \\
\text { Ferraz }\end{array}$ & 1940 \\
\hline & 83 & Wallace, Edgar & A pista da vela dobrada & Cristovam Paledzky & 1939 \\
\hline & 84 & Wallace, Edgar & Os olhos velados de Londres & Lourival Cunha & 1939 \\
\hline & 85 & Wallace, Edgar & O caso do delator & Luiz Estrella & 1940 \\
\hline & 86 & Rohmer, Sax & Quando a morte ri & Isaac Soares & 1942 \\
\hline & 87 & Wallace, Edgar & O hotel do terror & Luiza Ferreira & 1940 \\
\hline & 88 & Packard, Frank L. & Jimmie Dale e o fantasma & $\begin{array}{l}\text { Homero de Castro } \\
\text { Jobim }\end{array}$ & 1942 \\
\hline & 89 & Wallace, Edgar & Os ases vermelhos & Pepita de Leão & 1941 \\
\hline & 90 & Fletcher, J. S. & Os diamantes fatais & Hamilcar de Garcia & 1943 \\
\hline & 91 & Wallace, Edgar & Sanders da África & Mario Quintana & 1940 \\
\hline & 92 & $\begin{array}{l}\text { Crofts, Freeman } \\
\text { Wills }\end{array}$ & A tragédia de Starvel & Marques Rebello & 1940 \\
\hline & 93 & Horler, Sydney & Coração negro & Dias da Costa & 1941 \\
\hline & 94 & Mavity, Nancy Barr & $\begin{array}{l}\text { O homem que não temia a } \\
\text { forca }\end{array}$ & Carlos Casanovas & 1942 \\
\hline & 95 & Wallace, Edgar & A lei dos 4 homens justos & Leonel Vallandro & 1940 \\
\hline & 96 & Horler, Sydney & A volta de Vivanti & Marques Rebello & 1942 \\
\hline & 97 & Schultz, Walther & $\begin{array}{l}\text { O luar assassino/ O caso de } \\
\text { Dagmar Michaelis }\end{array}$ & [Autor brasileiro] & 1941 \\
\hline & 98 & Sintair \& Steeman & A $13^{a}$ pancada da meia-noite & Dorval Serrano & 1941 \\
\hline & 99 & Eberhart, Mignon G. & O crime do hospital & $\mathrm{N} / \mathrm{C}$ & 1941 \\
\hline & 100 & Bentley, E. C. & O último caso de Trent & Hamilcar de Garcia & 1943 \\
\hline & 101 & Christie, Agatha & O caso dos dez negrinhos & Leonel Vallandro & 1942 \\
\hline & 102 & Quentin, Patrick & Um enigma para doidos & Hamilcar de Garcia & 1943 \\
\hline & 103 & Sapper & Knock-out & Isaac Soares & 1943 \\
\hline & 104 & Knight, Clifford & O caranguejo escarlate & Hamilcar de Garcia & 1943 \\
\hline & 105 & Christie, Agatha & A morte no Nilo & Ligia Junqueira Smith & 1944 \\
\hline & 106 & Crofts, F. Wills & O grande caso de French & Idalina Peçanha Dias & 1943 \\
\hline & 107 & $\begin{array}{l}\text { Mason, Van Vick } \\
\text { [sic] }\end{array}$ & A morte dança na Rumânia & Hamilcar de Garcia & 1943 \\
\hline
\end{tabular}




\begin{tabular}{|c|c|c|c|c|}
\hline 108 & Mavity, Nancy Barr & $\begin{array}{l}\text { O caso das sandálias } \\
\text { perdidas }\end{array}$ & T. de Ernani Seabra & 1944 \\
\hline 109 & Gardner, Erle Stanley & O caso das garras de veludo & Hamilcar de Garcia & 1943 \\
\hline 110 & Queen, Ellery & $\begin{array}{l}\text { O mistério dos fósforos } \\
\text { queimados }\end{array}$ & Wilson Velloso & 1945 \\
\hline 111 & Gardner, Erle Stanley & O caso da jovem arisca & Marcello de Andrade & 1944 \\
\hline 112 & Myers, Isabel Briggs & A morte se faz anunciar & Wilson Velloso & 1944 \\
\hline 113 & Gardner, Erle Stanley & O caso das pernas de sorte & Leonel Vallandro & 1943 \\
\hline 114 & Dickson, Carter & Os crimes da viúva vermelha & Wilson Velloso & 1944 \\
\hline 115 & Gardner, Erle Stanley & O caso do cão uivador & Sonia Guimarães & 1944 \\
\hline 116 & Queen, Ellery & Um crime de encomenda & Lino Vallandro & 1944 \\
\hline 117 & Gardner, Erle Stanley & O caso da noiva curiosa & Marcello de Andrade & 1943 \\
\hline 118 & Dickson, Carter & A polícia é convidada & Eunice Catunda & 1944 \\
\hline 119 & Gardner, Erle Stanley & O caso do olho de vidro & Lino Vallandro & 1945 \\
\hline 120 & Christie, Agatha & Os cinco porquinhos & Edson Ferreira Santos & 1945 \\
\hline 121 & Gardner, Erle Stanley & O caso do gato do porteiro & Vidal de Oliveira & 1944 \\
\hline 122 & Irish, William & A mulher fantasma & Wilson Velloso & 1944 \\
\hline 123 & Gardner, Erle Stanley & $\begin{array}{l}\text { O caso da sobrinha do } \\
\text { sonâmbulo }\end{array}$ & Afrânio Zucoloto & 1942 \\
\hline 124 & Hammett, Dashiell & Estranha maldição & Wilson Velloso & 1946 \\
\hline 125 & Inexistente & Inexistente & & \\
\hline 126 & Hammett, Dashiell & Safra vermelha & Lino Vallandro & 1946 \\
\hline 127 & Queen, Ellery & O diabo que resolva & Cecília Whately & 1947 \\
\hline 128 & Hammett, Dashiell & O falcão maltês & Candida Villalva & 1945 \\
\hline 129 & Queen, Ellery & $\begin{array}{l}\text { O mistério do sapato } \\
\text { holandês }\end{array}$ & Lino Vallandro & 1947 \\
\hline 130 & Hammett, Dashiell & A chave de vidro & Silvia Mendes Cajado & 1945 \\
\hline 131 & Irish, William & Prisioneiros da madrugada & Adelaide Silveira & 1947 \\
\hline 132 & Queen, Ellery & O mistério da tangerina & James Amado & 1948 \\
\hline 133 & Paul, Elliot & O Louvre em polvorosa & Clementino de Alencar & 1947 \\
\hline 134 & Queen, Ellery & O mistério do ataúde grego & Lino Vallandro & 1947 \\
\hline 135 & Paul, Elliot & Homicídio em si bemol & Homero de Castro & 1948 \\
\hline
\end{tabular}




\begin{tabular}{|c|c|c|c|c|}
\hline & & & Jobim & \\
\hline 136 & Queen, Ellery & A porta do meio & Wilson Velloso & 1949 \\
\hline 137 & Christie, Agatha & O segredo de Chimneys & Faustino Armando & 1948 \\
\hline 138 & Christie, Agatha & O secreto adversário & Isaac Soares & 1949 \\
\hline 139 & Patrick, Quentin & A morte e a donzela & Faustino Armando & 1949 \\
\hline 140 & Stout, Rex & A caixa vermelha & Isaac Soares & 1950 \\
\hline 141 & Wallace, Edgar & O círculo vermelho & $\begin{array}{l}\text { Darcy Azambuja [reed. } \\
\text { v. 1] }\end{array}$ & 1951 \\
\hline 142 & Hilton, James & Tragédia no internato & Lino Vallandro & 1951 \\
\hline 143 & Roos, Kelley & Mortalha sob medida & $\begin{array}{l}\text { Faustino Armando/ } \\
\text { Isaac Soares }\end{array}$ & 1951 \\
\hline 144 & Christie, Agatha & O homem da roupa marrom & $\begin{array}{l}\text { Homero de Castro } \\
\text { Jobim/ "Gilberto } \\
\text { Miranda" }\end{array}$ & 1951 \\
\hline 145 & Wallace, Edgar & O bando terrível & A. Duprat [reed. v. 4] & 1951 \\
\hline 146 & Christie, Agatha & $\begin{array}{l}\text { O assassinato de Roger } \\
\text { Ackroyd }\end{array}$ & $\begin{array}{l}\text { Heitor Berutti [reed. v. } \\
29 \text { ] }\end{array}$ & 1951 \\
\hline 147 & Brown, Fredric & O tio prodigioso & Mario Quintana & 1951 \\
\hline 148 & Queen, Ellery & A tragédia de $X$ & "Gilberto Miranda" & 1951 \\
\hline 149 & Queen, Ellery & O crime da raposa & $\begin{array}{l}\text { Herbert Caro/Isaac } \\
\text { Soares }\end{array}$ & 1952 \\
\hline 150 & Sayers, Dorothy & O crime exige propaganda & Wilson Velloso & 1952 \\
\hline 151 & Simenon, Georges & A amiga de Madame Maigret & Vidal de Oliveira & 1952 \\
\hline 152 & Wallace, Edgar & O homem sinistro & $\begin{array}{l}\text { Erico Verissimo [reed. } \\
\text { v. 6] }\end{array}$ & 1953 \\
\hline 153 & Simenon, Georges & Os fantasmas do chapeleiro & Mario Quintana & 1954 \\
\hline 154 & Simenon, Georges & A sombra chinesa & Mario Quintana & 1954 \\
\hline 155 & Wallace, Edgar & A porta das sete chaves & $\begin{array}{l}\text { Pedro Bruno Dischinger } \\
\text { [reed. v. 2] }\end{array}$ & 1954 \\
\hline 156 & Simenon, Georges & Maigret e seu morto & Vidal de Oliveira & 1956 \\
\hline 157 & Wallace, Edgar & A pista do alfinete novo & $\begin{array}{l}\text { Erico Verissimo [reed. } \\
\text { v. 24] }\end{array}$ & 1956 \\
\hline
\end{tabular}




\begin{tabular}{|c|l|l|l|c|}
\hline 158 & Simenon, Georges & A estréia de Maigret & Marcello Magalhães & 1956 \\
\hline 159 & Christie, Agatha & O caso dos dez negrinhos & $\begin{array}{l}\text { Leonel Vallandro [reed. } \\
\text { v. 101] }\end{array}$ & 1956 \\
\hline
\end{tabular}

\section{Iconografia}

Abaixo, seguem-se as imagens de capa da primeira edição de todos os volumes lançados na Coleção Amarela, do número 1 ao número 159.

Apesar da ampla variedade dos partidos visuais adotados, há de se notar que foi a partir do número 100 - O último caso de Trent - que se adotou o logo que veio a se tornar tão característico da coleção, a ponto de ser o único elemento visual a permanecer quando de sua retomada editorial nos anos 1980: o homenzinho estilizado, de boné e punhal na mão, com o tronco em forma de C (para "Coleção") e as pernas em forma de A (para "Amarela").

Há de se notar também que foi a partir do número 143 - Mortalha sob medida - que se adotou o layout de capa que se manteria até o final da coleção: uma larga faixa amarela superior, ocupando um terço da frente de capa, e uma estreita faixa amarela inferior, com nome/logo da coleção e nome/local da editora. 
Volumes 1 a 12:
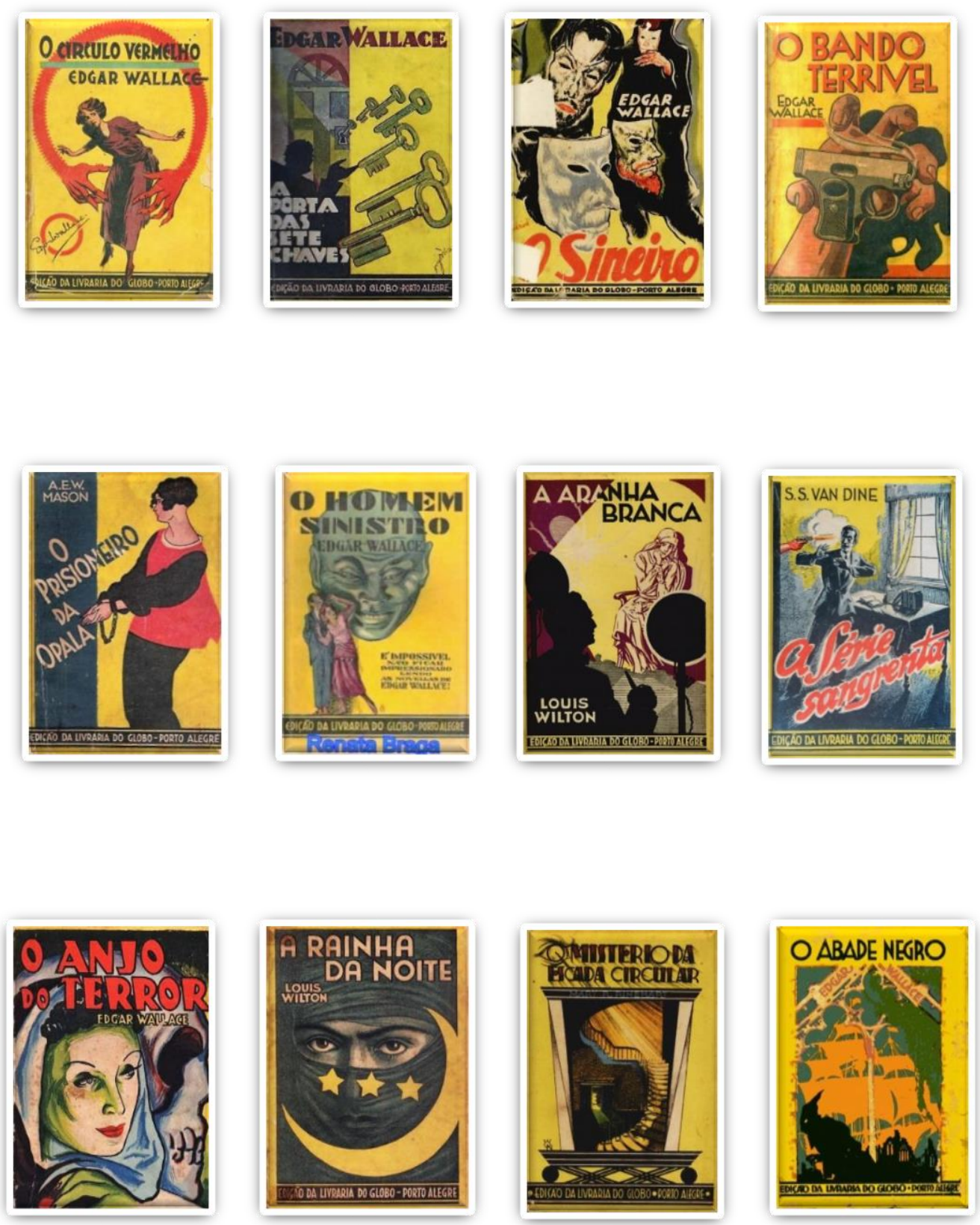
Volumes 13 a 24:
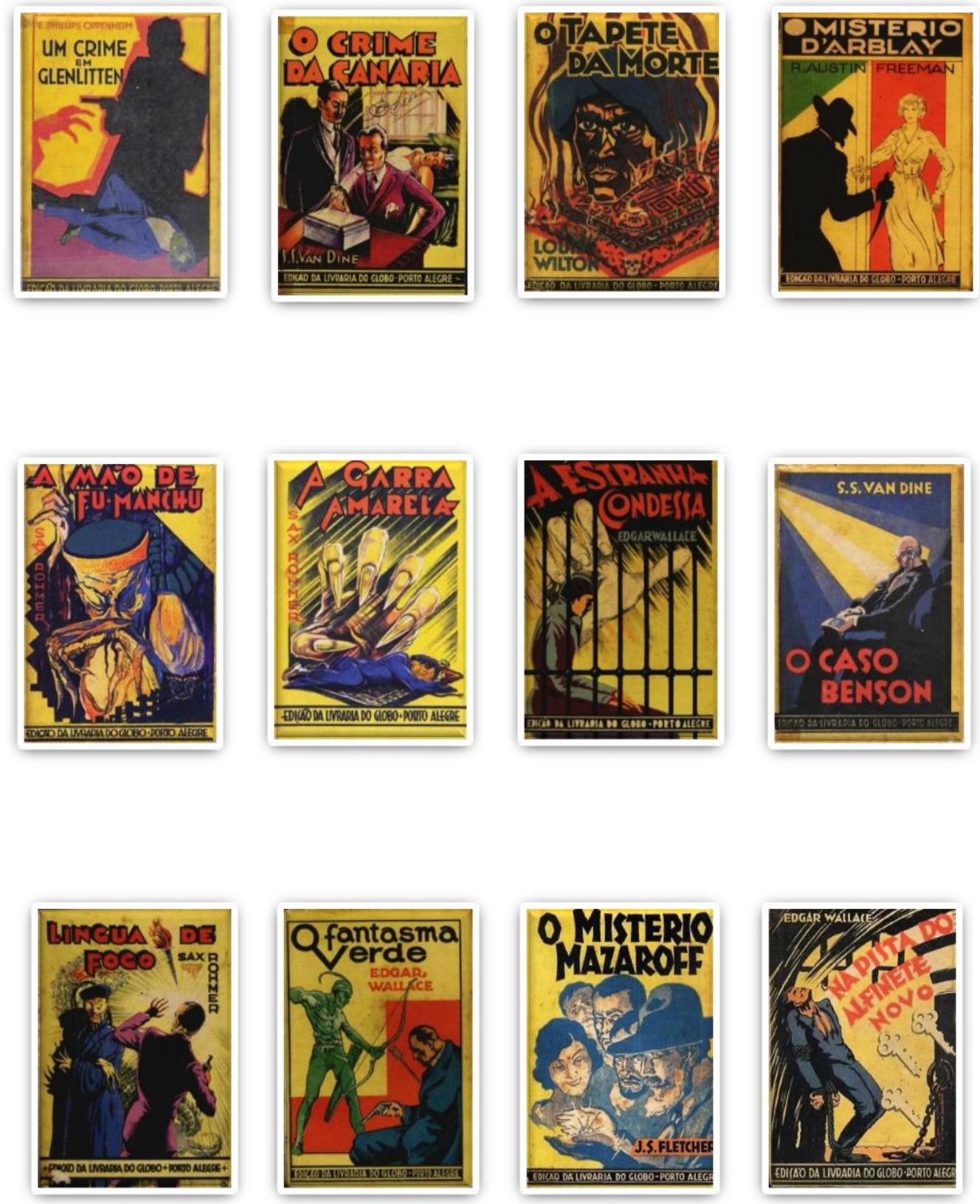
Volumes 25 a 36:
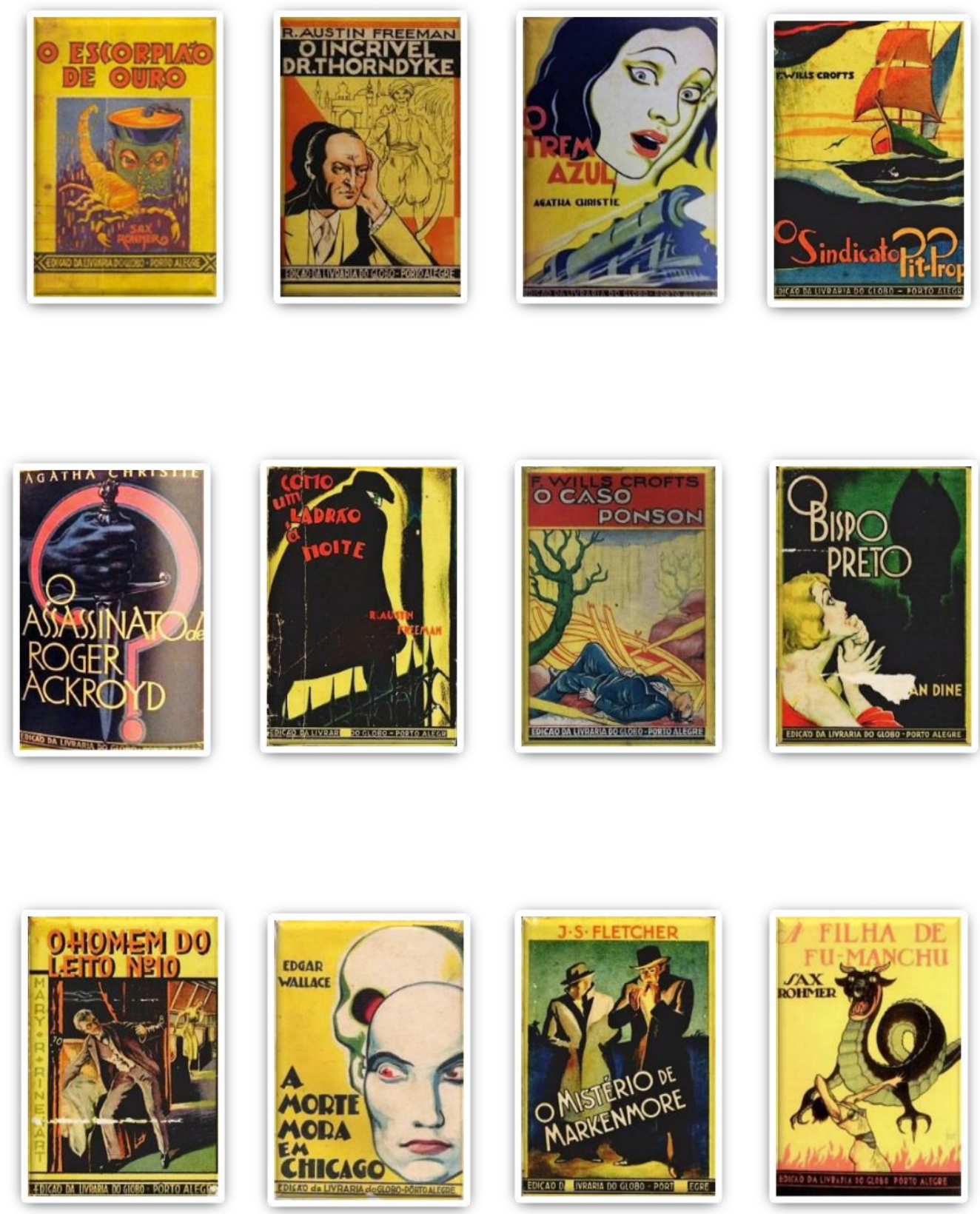
Volumes 37 a 48:
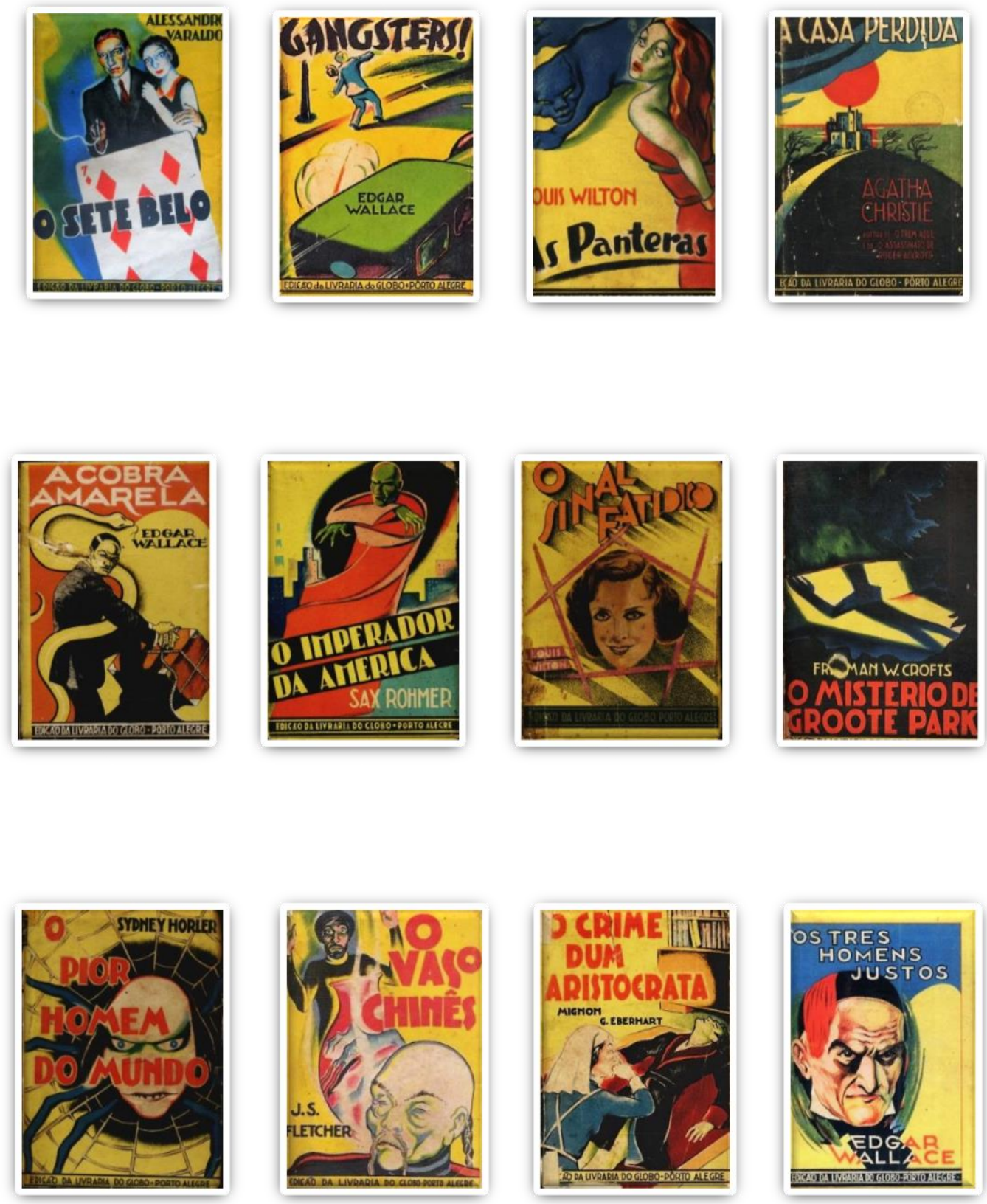
Volumes 49 a 60 :
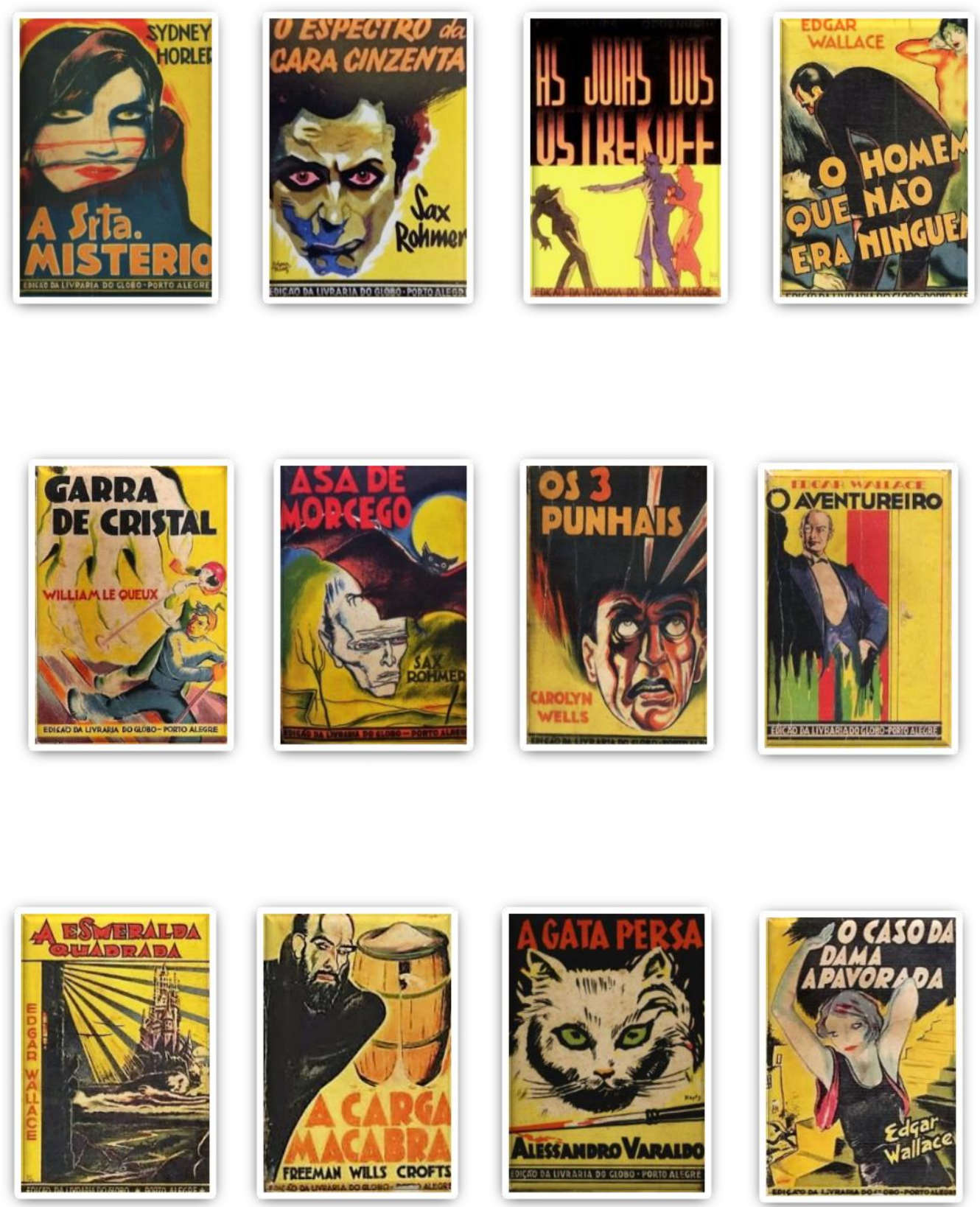
Volumes 61 a 72 :
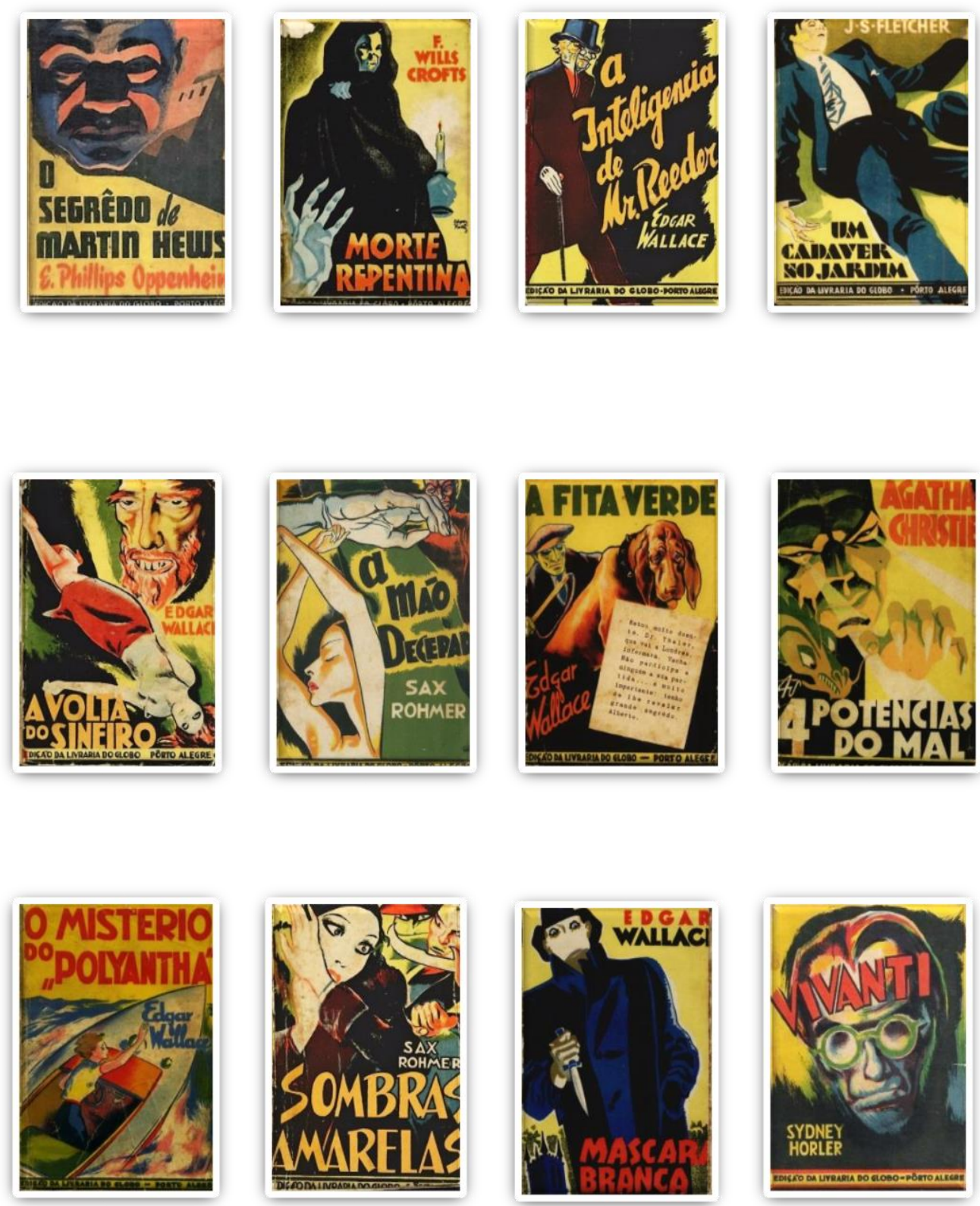
Volumes 73 a 84:
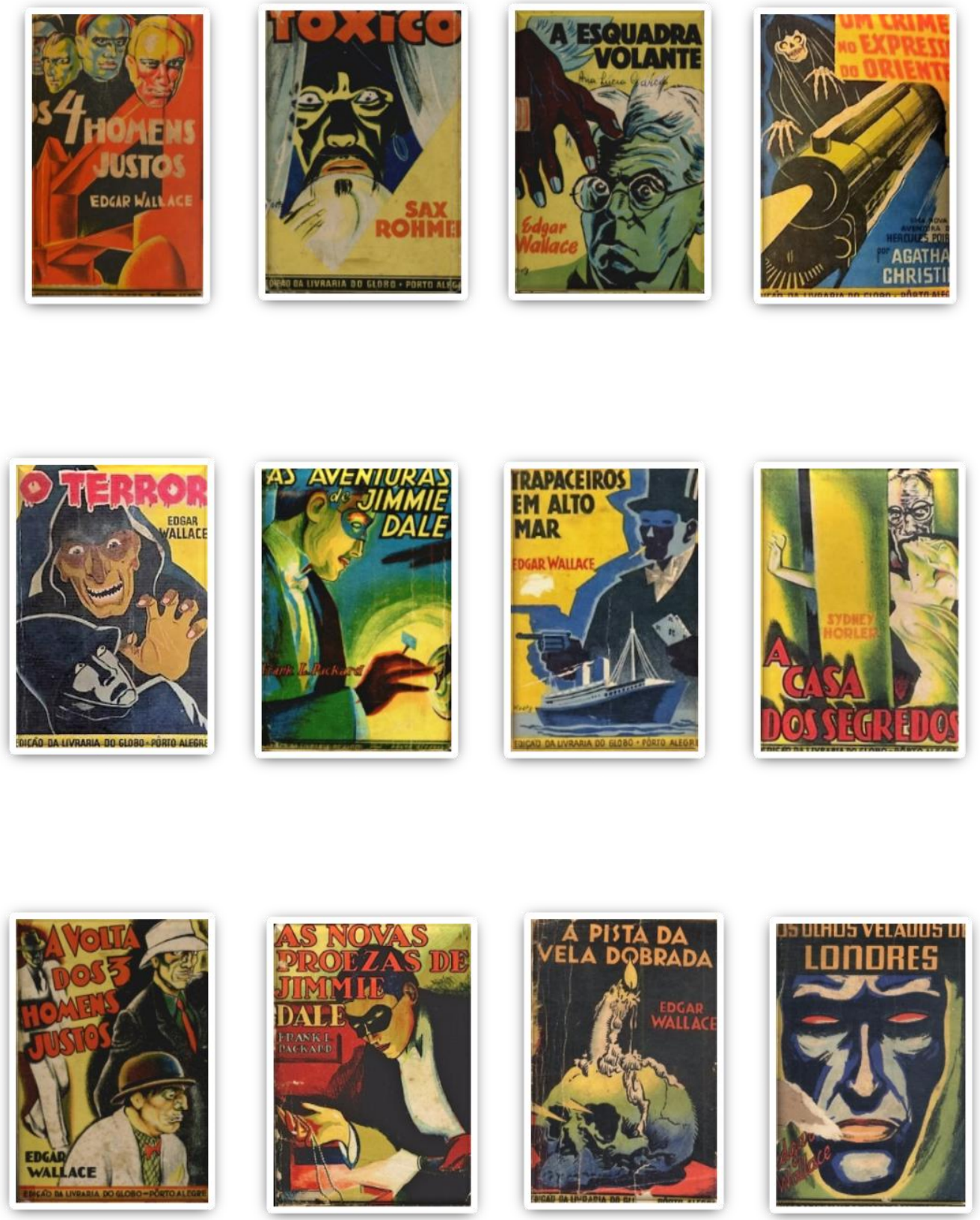
Volumes 85 a 96:
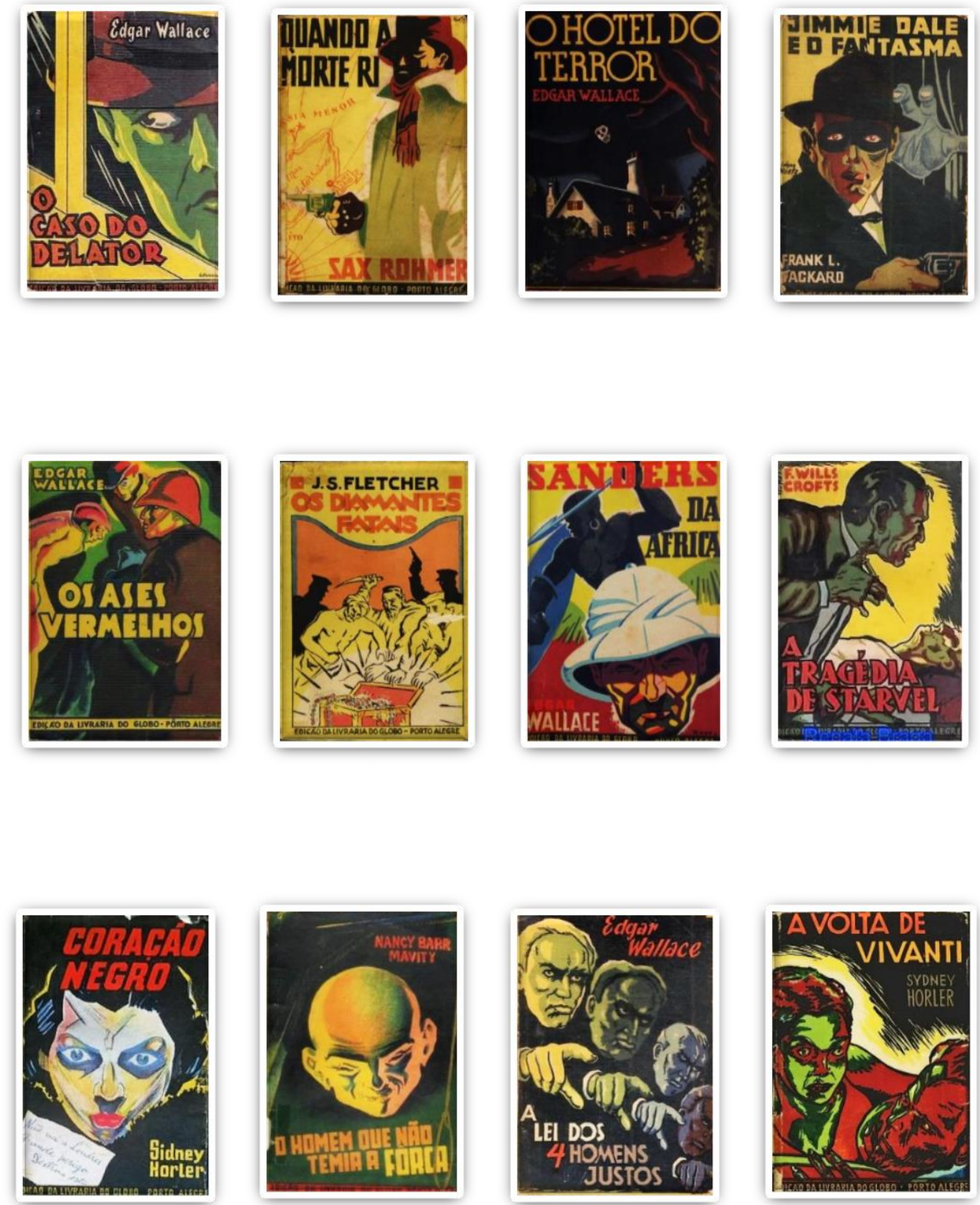
Volumes 97 a 108:
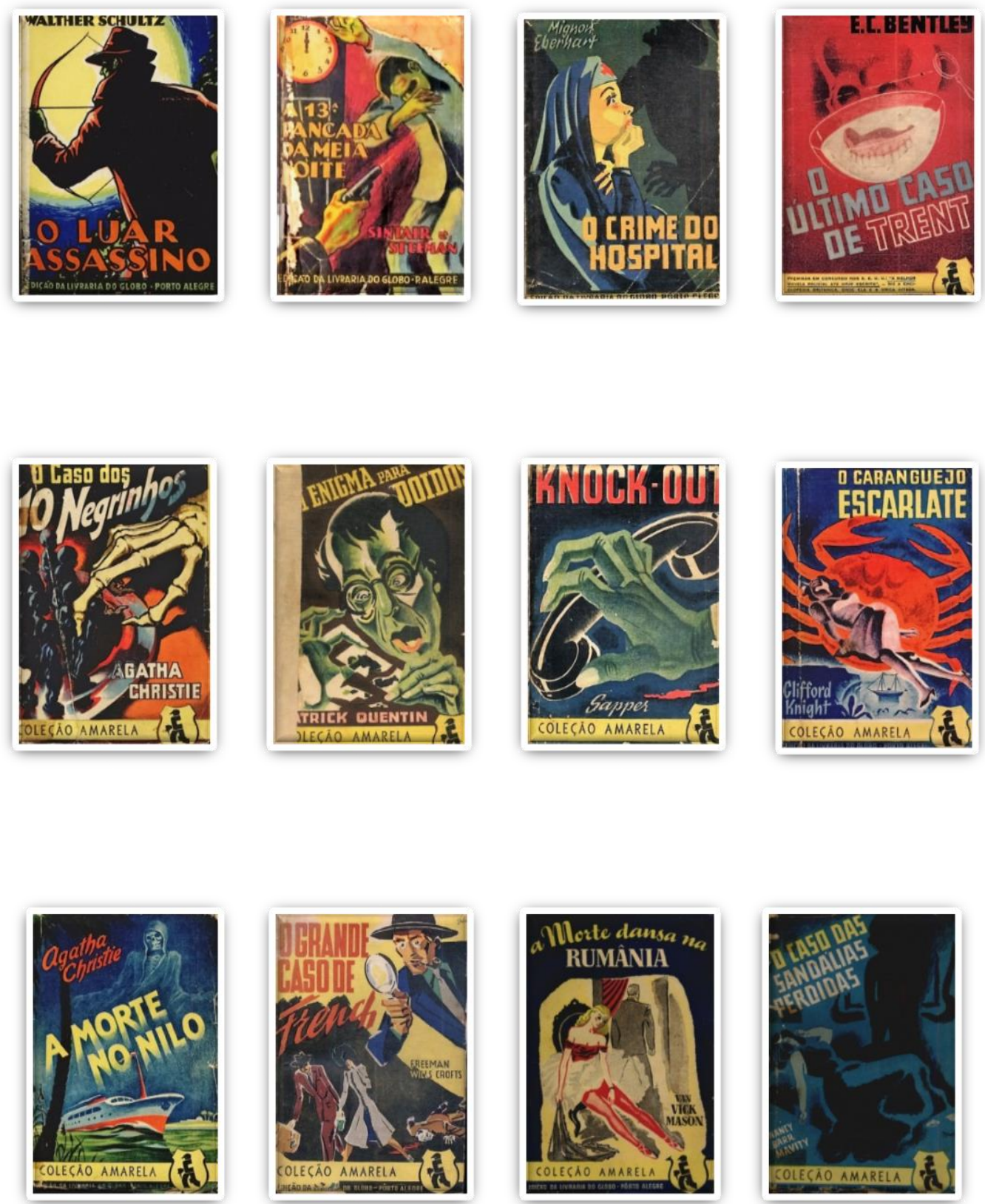
Volumes 109 a 120:
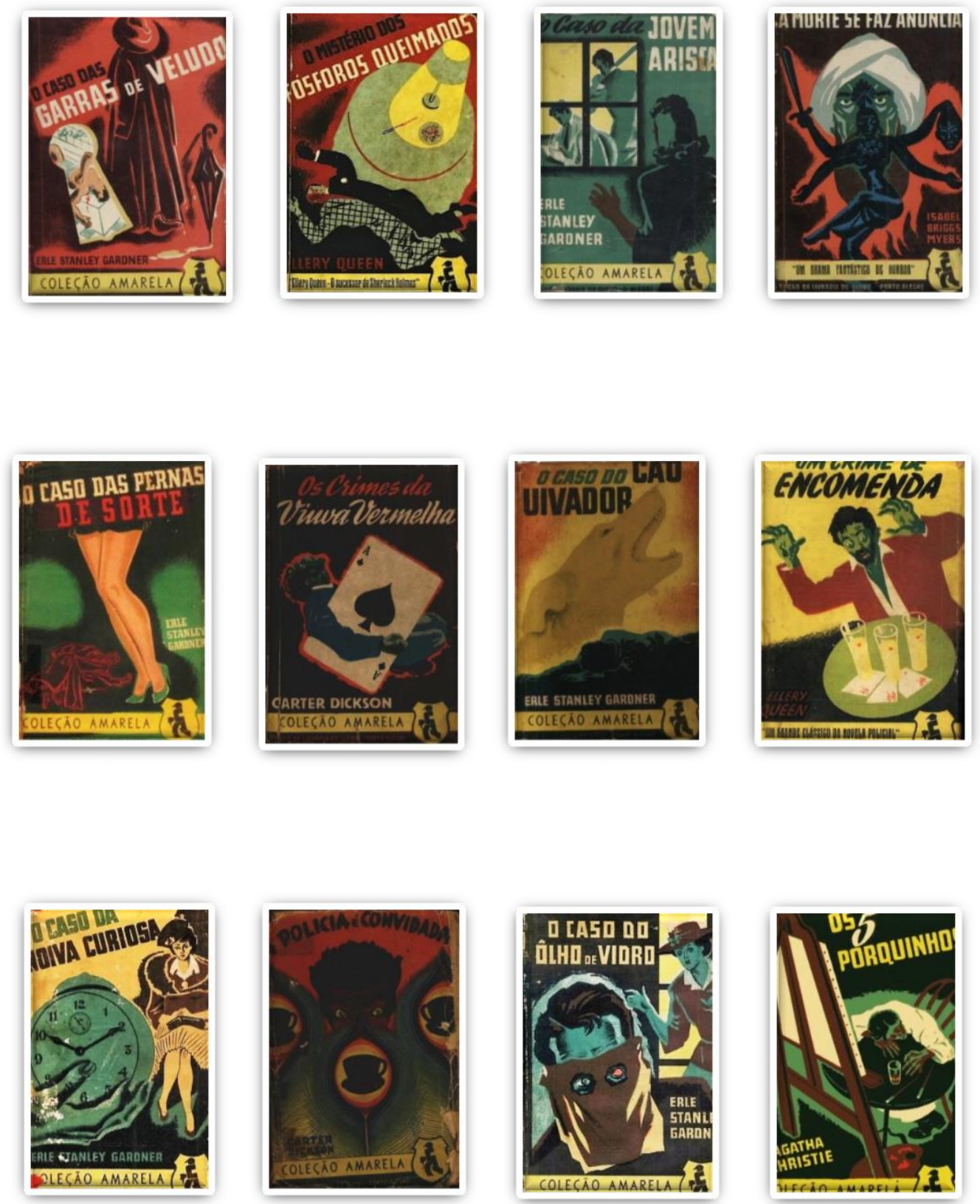
Volumes 121 a 132:
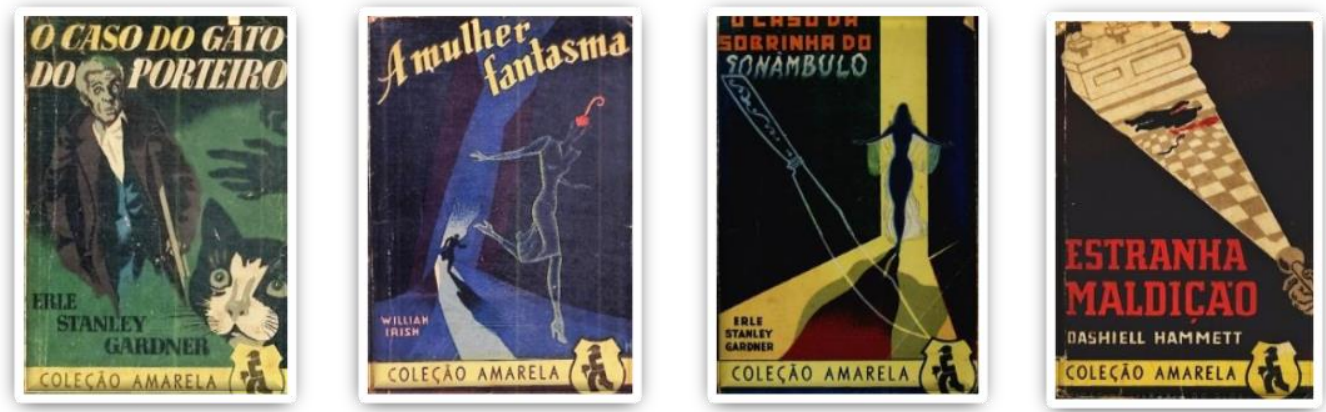

232
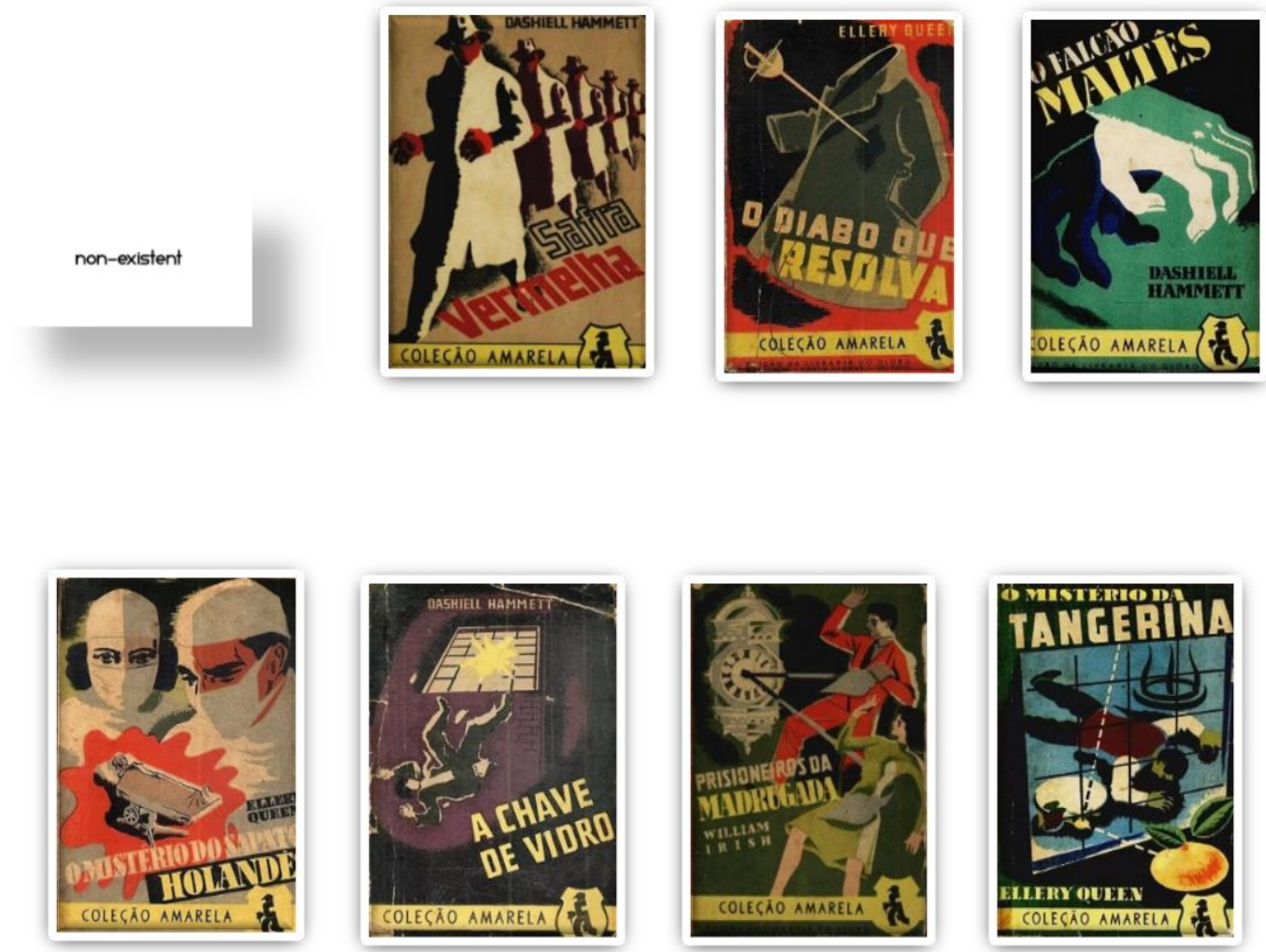
Volumes 133 a 144:
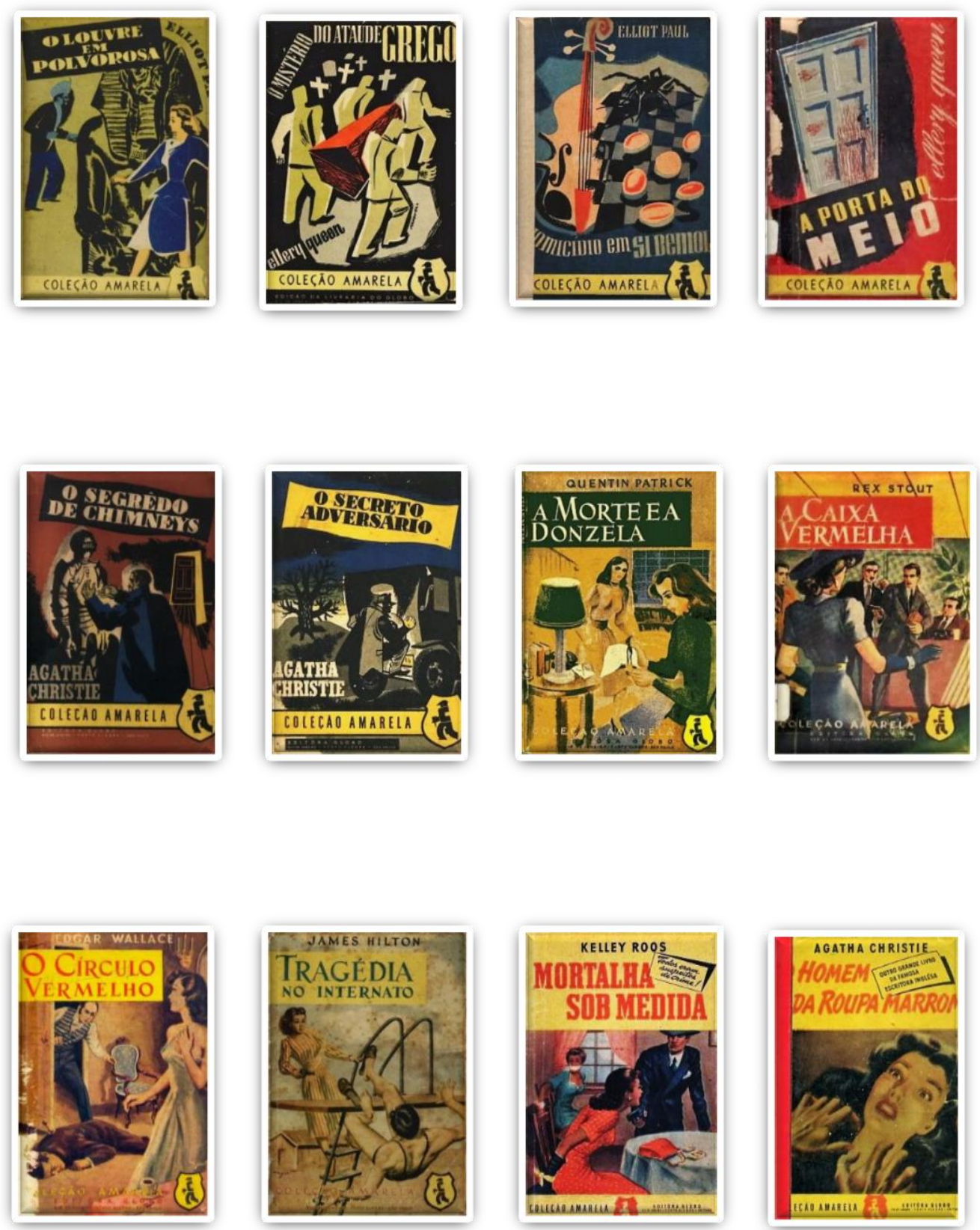
Volumes 145 a 156:
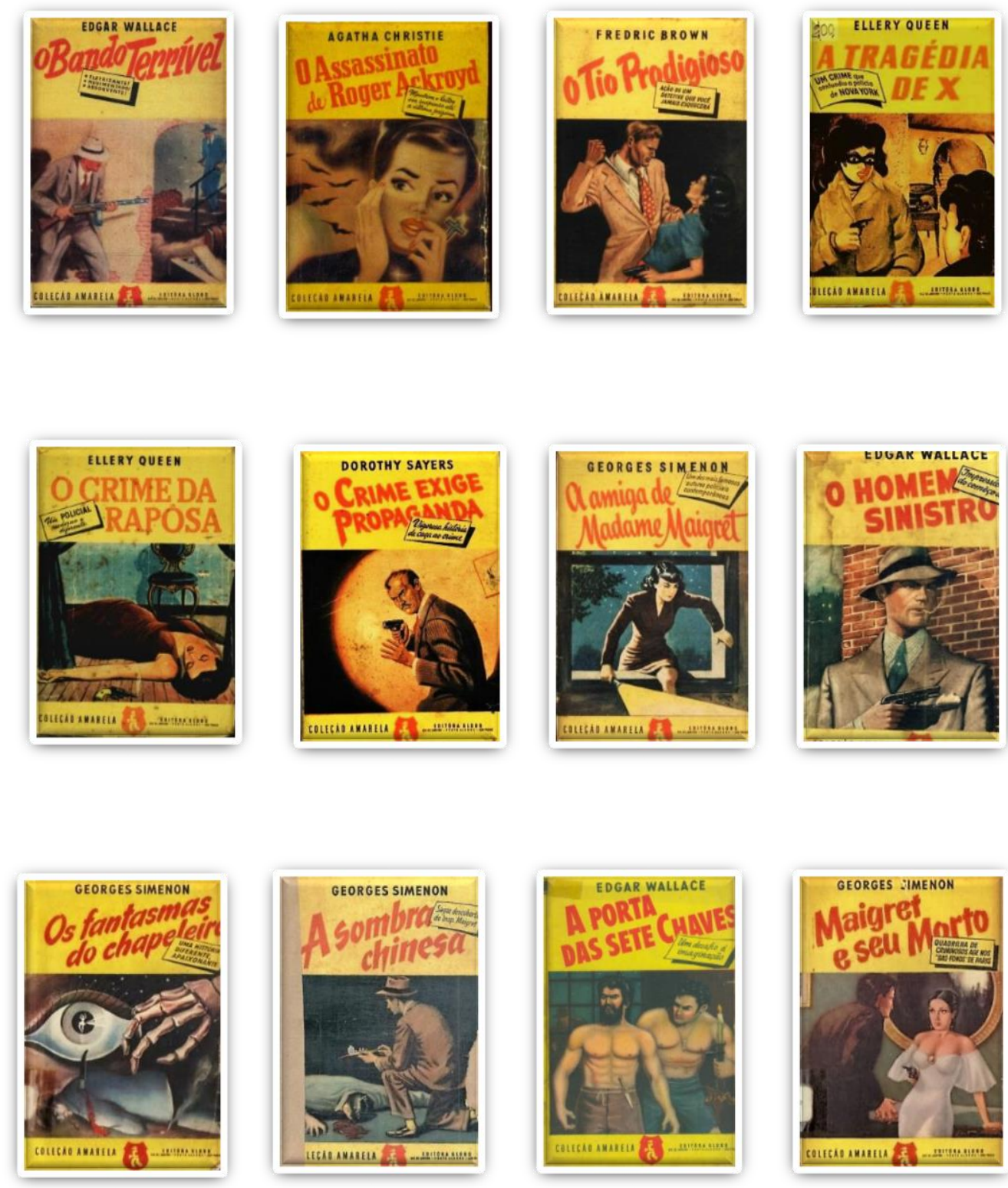

Volumes 157 a 159:
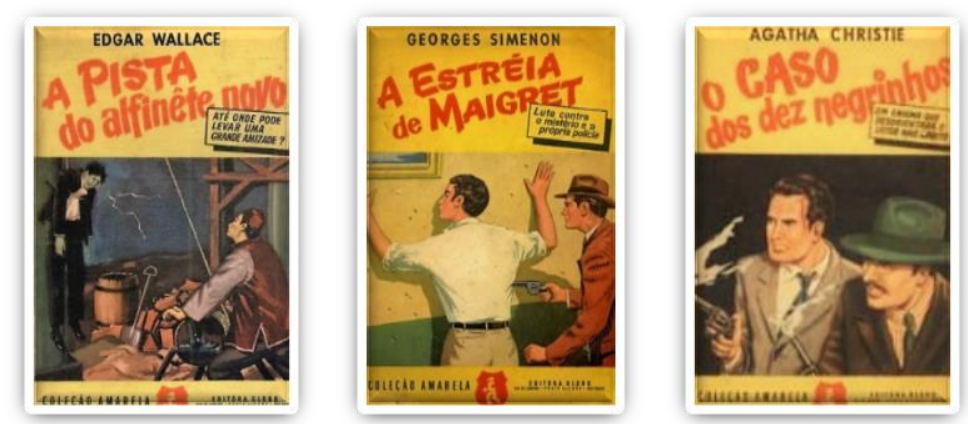


\section{Considerações finais}

Ao longo do tempo, a Coleção Amarela transformou-se numa espécie de mito entre os apreciadores da literatura policial no Brasil, e deve-se dizer que essa aura mítica contribuiu para a disseminação de muitas informações equivocadas a respeito da coleção. Um dos objetivos deste levantamento é exatamente contribuir, na medida do possível, para retificar algumas destas informações, apresentando dados mais fidedignos. Para maiores detalhes, pode-se consultar o blog criado especialmente para divulgar os resultados desta pesquisa, no endereço http://colecaoamarela.blogspot.com.br/.

\section{Fontes de consulta}

Para as fontes primárias, foram consultadas a Biblioteca Nacional, a Hemeroteca Digital da Fundação Biblioteca Nacional, livrarias físicas e virtuais e coleções pessoais.

Como fontes secundárias, foram de grande valia:

AMORIM, Sônia Maria de. Em busca de um tempo perdido. São Paulo: EDUSP; Com-Arte; Porto Alegre: Editora UFRGS, 1999.

HALEWELL, Laurence. O livro no Brasil. Trad. Maria da Penha Villalobos, Lólio Lourenço de Oliveira e Geraldo Gerson de Souza. 2a . ed. revista e ampliada. São Paulo: EDUSP, 2005.

MEDEIROS E ALBURQUERQUE, Paulo. O mundo emocionante do romance policial. Rio de Janeiro: Francisco Alves, 1979.

RAMOS, Paula Viviane. A modernidade impressa. Porto Alegre: Editora UFRGS, 2016.

VERISSIMO, Erico. Um certo Henrique Bertaso. São Paulo: Companhia das Letras, 2011.

Ademais, encontram-se importantes materiais dispersos em vários sites e blogues.

\section{Agradecimentos}

Deixamos aqui nossos agradecimentos a várias pessoas que contribuíram com informações e referências preciosas, em especial a Paulo Tadeu Luccas, Bráulio Tavares, Luís Queirós, Tito Prates e Carlos Henrique Besen.

\footnotetext{
i Levantamento disponível no blog A COLEÇÃO AMARELA DA LIVRARIA DO GLOBO (1931-1956). Disponível em: http://colecaoamarela.blogspot.com.br/?view=classic

ii Sérgio Bandeira KARAM - Graduado em Letras - Tradução do Inglês (1999) pela Universidade Federal do Rio Grande do Sul (UFRGS).

Currículo Lattes Sérgio Bandeira KARAM. Disponível em: http://lattes.cnpq.br/4507175726951656
} 
iii Denise Guimarães BOTTMANN: Graduada em História (1981) pela Universidade Federal do Paraná (UFPR). Mestre em História (1985) pela Universidade Estadual de Campinas (Unicamp).

Currículo Lattes Denise Guimarães BOTTMANN. Disponível em: http://lattes.cnpq.br/4979718236781288

RECEBIDO EM: 13 de agosto de 2016

ACEITO EM: 28 de novembro de 2016

PUBLICADO EM: Dezembro de 2016 